\title{
How to Ventilate Lungs as Small as $12.5 \%$ of Normal: The New Technique of Intratracheal Pulmonary Ventilation
}

\author{
ECKHARD E. MÜLLER.' THEODOR KOLOBOW. SRINIVAS MANDAVA. MICHAEL JONES. \\ GIOVANNI VITALE, MICHELE APRIGLIANO, AND KOJI YAMADA \\ Section on Pulmonary and Cardiac Assist Devices, Laboratory of C'all Biology: National Heart. Lung. and Blood \\ Institute. National Institute's of Health, Bethexda, Marytand 20892
}

\begin{abstract}
ABSTRACI. We wished to determine in a laboratory animal model how much residual lung was needed to sustain total gas exchange. In a series of young, healthy lambs weighing approximately $10 \mathrm{~kg}$ that were sedated and paralyzed, we progressively excluded from gas exchange all the left lung (a total of $\mathbf{4 3 \%}$ ), plus the right lower and cardiac lobes $(81 \%)$, plus the right middle lobe $(87.5 \%)$. In some studies, the respective lobes were surgically removed; in others, the bronchi and the pulmonary arteries to the respective lobes were ligated. We provided pulmonary ventilation using the pressure control mode (Servo $900 \mathrm{C}$ ) at a tidal volume of $20 \mathrm{~mL} / \mathrm{kg}$ multiplied by the fraction of the remaining lungs, a respiratory rate up to $120 / \mathrm{min}$, a peak inspiratory pressure of $12-15 \mathrm{~cm} \mathrm{H}_{2} \mathrm{O}$, and a positive end-expiratory pressure of $3 \mathrm{~cm} \mathrm{I}_{2} \mathrm{O}$. Those lambs with at least both the right upper lobe (RUL) and right middle lobe remaining ( $19 \%$ of total lungs) were weaned to room air on mechanical ventilation within $48 \mathrm{~h}$. Ventilating RUL (12.5\% of remaining lung) with the same ventilator required a substantially higher tidal volume and peak inspiratory pressure to result in adequate alveolar ventilation but led to respiratory failure and death within $8 \mathrm{~h}$. We then applied a newly developed system of intratracheal pulmonary ventilation to ventilate the RUL (12.5\% of remaining lung) alone. $A$ continuous flow of humidified mixture of air and oxygen was directly passed into the trachea at the level of the carina through a diffuser at a tidal volume of $2.5 \mathrm{~mL} / \mathrm{kg}$. A single valve controlled expiration and respiratory rate. Lambs with only RUL remaining were weaned to room air within $2 \mathrm{~h}$, at a respiratory rate of 60-120/min and peak inspiratory pressure of 14-9 $\mathrm{cm} \mathrm{H}_{2} \mathrm{O}$, inspiration to expiration ratio of $1: 1$, and positive end-expiratory pressure of $3 \mathrm{~cm} \mathrm{H}_{2} \mathrm{O}$. Initial mean pulmonary artery pressure progressively decreased from $40 \pm$ 5 to $25 \pm 7 \mathrm{~mm} \mathrm{IIg}$ within $6 \mathrm{~h}$ after surgery. (Pediatr Res 34: $606-610,1993$ )
\end{abstract}

\section{Abbreviations}

CMIV, controlled mechanical ventilation $\mathrm{FiO}_{2}$, inspired oxygen concentration

I:E ratio, inspiration to expiration ratio

ITPV, intratracheal pulmonary ventilation

MV, mechanical ventilation

PEEP, positive end-expiratory pressure

Received September 16, 1992: accepted June 9. 1993.

Correspondence: Theodor Kolobow. M.D.. National Institutes of Health. NHLBI, LCB, Building 10, Room 5 D 17,9000 Rockville Pike, Bethesda, MD 20892.

'Current address: Department of Anesthesiology and Intensive Care Theraps: Philipps-University Hospital, Baldingerstrasse 1. D-W-3550 Marburg/Lahn. Germany.

\author{
PIP, peak inspiratory pressure \\ $\mathrm{RR}$, respiratory rate \\ RUL, right upper lobe \\ $V T$, tidal volume \\ $\mathrm{PaO}_{2}$, arterial $\mathrm{O}_{2}$ tension \\ $\mathrm{PaCO}_{2}$, arterial $\mathrm{CO}_{2}$ tension
}

There are no reliable experimental data that show how much lung tissue can be surgically removed while still sustaining total blood gas exchange. In experiments in dogs, it was shown that survival in awake animals was not possible when greater than 75\% of the total lung parenchyma was surgically resected, with death resulting from pulmonary edema (1). Those studies had also shown a lack of adaptation, even if resection was undertaken in two steps after an interval of 6 wk.

In a laboratory animal model using anesthetized, paralyzed, healthy lambs. we explored what minimal fraction of normal lung was needed to sustain normal gas exchange. We also explored whether pulmonary deterioration was primarily related to the fraction of the lungs remaining or to other factors. such as the method of MV.

In the studies reported here, using healthy young lambs, we excluded from gas exchange progressively more lobes of the lungs, and we then attempted to sustain pulmonary ventilation using the remaining lobes of the lungs. With $12.5 \%$ of lungs remaining, the use of conventional $\mathrm{MV}$ resulted in progressive $\mathrm{CO}_{2}$ retention and hypoxia, whereas aggressive management led to respiratory failure and death. Under identical circumstances, the application of the newly developed technique of ITPV permitted weaning to room air ventilation within a few hours at normal peak airway pressures.

\section{MATERIALS AND METHODS}

These studies were conducted in anesthetized, paralyzed young sheep. Proper animal care was taken according to the NIII Guide for the Care and Use' of Laboratory Animals. The protocol of this study was approved by the NIH Animal Care and Use Committee. The studies were divided into two parts.

Group l: resection studies $(n=4)$. Through left and/or right thoracotomy and using sterile surgical techniques, we removed progressively more lung, in the following order: $l$ ) the left lung (estimated remaining lung: $57 \%$ of normal) $(n=1) ; 2)$ left lung plus RUL (estimated remaining lung: $44.5 \%$ of normal) $(n=1)$; and 3 ) left lung plus right lower and accessory lobes (estimated remaining lung: $19 \%$ of normal) $(n=2)$ (Fig. 1).

We used standard surgical techniques of thoracotomy and pneumonectomy, and resection of lung segments where appro- 


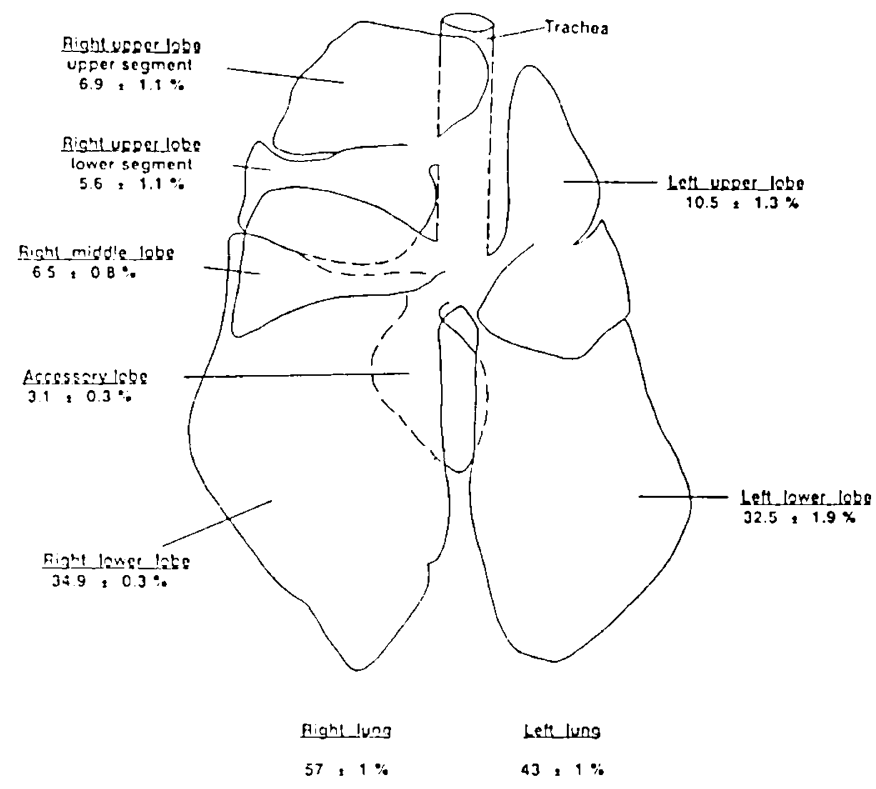

Fig. 1. The lobes of the lung of the sheep (in percent; total lung = $100 \%)(n=21)$.

priate. We took particular care to avoid damage to the remaining lung. During closure of the chest, a chest drain was inserted but left open and not connected to suction.

Group) 2: ligation studies $(n=6)$. This approach was designed to provide the least possible impairment to lung function from surgical intervention in areas adjacent to the RUL. In studies similar to those reported in group 1 lambs, we had found that surgical resection for the removal of all but the RUL resulted in some impairment in lymphatic and arterial flow and in impairment in venous drainage. This invariably compromised the lower segment of the RUL with severe edema, atelectasis, and hemorrhage, which we wished to avoid.

Through a right-sided thoracotomy, we first ligated the respective pulmonary arteries and bronchi to all but the RUL, leaving those so-ligated lobes in situ. After this, through a left-sided thoracotomy, we ligated the pulmonary artery to the left lung. The ductus arteriosus was routinely ligated. Finally, we ligated the trachea below the RUL bronchus, thereby totally isolating the left lung, the bronchi to all but the RUL having been previously ligated. The estimated fraction of lungs participating in gas exchange was thus reduced to $12.5 \%$. Chest drains were inserted as in group 1 and managed in a similar manner.

Anesthesia and general management. Anesthesia was induced with $5 \mathrm{mg}$ of diazepam and $20-30 \mathrm{mg} / \mathrm{kg}$ thiopental sodium i.v. After endotracheal intubation, the animals underwent general anesthesia. All sheep received continuous i.v. infusion of $0.9 \%$ $\mathrm{NaCl}$, alternating with $5 \%$ dextrose in water, at a rate of $8.3 \mathrm{~mL} /$ $\mathrm{kg} / \mathrm{h}$, adjusted as needed. Sodium bicarbonate was administered, as needed, to maintain base excess at greater than $-3 \mathrm{mmol} / \mathrm{L}$. The sheep were placed on a water blanket to control body temperature. The right carotid artery was cannulated for blood pressure monitoring and arterial blood sampling. A $5 \mathrm{~F}$ Swan Ganz thermodilution catheter was introduced percutaneously through the right external jugular vein and was advanced into the pulmonary artery. A tracheostomy was performed approximately $5 \mathrm{~cm}$ above the sternum and a tracheostomy tube $(6 \mathrm{~mm}$ inner diameter) was inserted. All sheep were then turned prone, and the body temperature was cooled to $34^{\circ} \mathrm{C}$ for the duration of the surgical procedure (as described above), after which the temperature was returned to $38^{\circ} \mathrm{C}$ for the remainder of the study. Ceftriaxone sodium was given in a dose of $0.5 \mathrm{~g} / 12 \mathrm{~h}$ i.v.

Monitoring. The hemodynamic variables, gas exchange, and body temperature were measured and recorded before. during. and after all surgical procedures on an hourly basis and more frequently when needed. Arterial, pulmonary artery, central ve- nous, and airway pressure at the level of the tracheostomy tube were continuously measured on transducers (Statham P 23 D, Gould Inc.) and recorded on an ink recorder (Type 200, model 2222, Gould Inc., Oxnard, CA). Arterial blood samples were analyzed on a gas analyzer (ABL 300. Radiometer. Copenhagen, Denmark).

Blood temperature was monitored via the thermodilution catheter using a cardiac output computer $(9520 \mathrm{~A}$. American Edwards Laboratories, Irvine, CA) and was adjusted through changes in water blanket temperatures (Blanketrol, Cincinnati Sub-Zero Products, Cincinnati, OH).

l'entilator management. We used two modes of pulmonary ventilation: conventional MV and ITPV.

Conventional $\mathrm{MV}$. Before, during, and after surgery, the lambs in group 1 were ventilated with a Servo ventilator $900 \mathrm{C}$ (Siemens Medical Systems, Iselin, NJ) in the pressure control mode. The VT was adjusted to keep PIP between 12 and $18 \mathrm{~cm} \mathrm{H}_{2} \mathrm{O}$. The VT was kept at $10 \mathrm{~mL} / \mathrm{kg}$ with the whole lung intact. During the resection and ligation studies in group I and II sheep, the VT was increased to $20 \mathrm{~mL} / \mathrm{kg}$ of body weight multiplied by the proportion of the lung remaining and participating in gas exchange. We adjusted RR up to $120 / \mathrm{min}$ and used a PEEP of 3 $\mathrm{cm} \mathrm{H}_{2} \mathrm{O}$ and an $\mathrm{I}: \mathrm{E}$ ratio of $1: 1$. We used a Concha-therm-III humidifier (Respiratory Care Inc., Arlington Heights, IL) for gas heating and humidification. We took special care to avoid water condensation by insulating gas tubing with multiple layers of plastic film.

ITPI: This method was developed to greatly reduce dead space ventilation, and was to be applied to group II lambs. We introduced through the endotracheal tube a small catheter with multiple perforations at its distal tip (diffuser), the diffuser resting at the level of the carina (Fig. 2). The gas flow through this catheter was continuous during both inspiration and expiration and was set at $5 \mathrm{~mL} / \mathrm{kg} /$ respiratory cycle. In a $10-\mathrm{kg}$ lamb. at an $\mathrm{I}:$ E ratio of $1: 1$, this gave an inspiratory $V T$ of $2.5 \mathrm{~mL} / \mathrm{kg}$ for RUL alone (equal to $20 \mathrm{~mL} / \mathrm{kg}$. times fraction of lungs remaining, as under conventional MV).

With the tracheal dead space greatly reduced or eliminated. we used an RR up to $120 / \mathrm{min}$ for enhanced alveolar ventilation. Iligh RR later allowed us to reduce VT to as low as $1.2 \mathrm{~mL} / \mathrm{kg}$ and to maintain low PIP (3-4 $\mathrm{cm} \mathrm{H}_{2} \mathrm{O}$ above PEEP) while still effecting adequate alveolar ventilation with normal $\mathrm{PaC} \mathrm{O}_{2}$ values (6.6-6.0 k Pa $/ 35-45 \mathrm{~mm} \mathrm{Hg}$ ).

We used this technique in combination with a Servo ventilator $900 \mathrm{C}$ with the air/oxygen supply to the ventilator disconnected. Using the pressure control mode. the inspiratory pressure above PEEP was set at zero. The expiratory valve of the Servo ventilator provided the desired PEEP $\left(3 \mathrm{~cm} \mathrm{H}_{2} \mathrm{O}\right), \mathrm{I}: \mathrm{E}$ ratio $(1: 1)$, and expiratory frequency (RR). With those settings, the inspiratory valve of the Servo ventilator remained closed. In essence. the Servo ventilator was used solely to control the expiratory valvo to make the system operable. FiO, was adjusted as needed to keep $\mathrm{PaO})_{2} \geq 6.7 \mathrm{kPa}(50 \mathrm{~mm} \mathrm{Hg})$.

Definition of endpoint. Successful weaning was based on the ability to tolerate room air ventilation at normal body temperatures, with $\mathrm{PaO}_{2} \geq 6.7 \mathrm{kPa}(50 \mathrm{~mm} \mathrm{Hg})$. FiO 20.21 . $\mathrm{PaCO}_{2} 4.6-6$

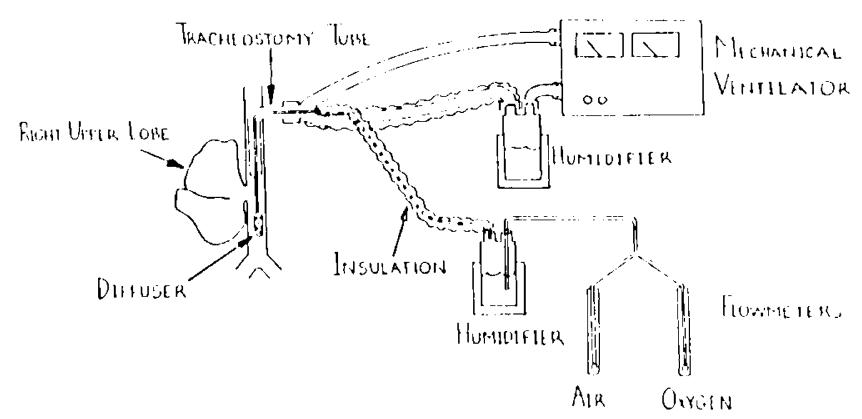

Fig. 2. Schematic of ITPV. See text for details. 
$\mathrm{kPa}\left(35-45 \mathrm{~mm} \mathrm{Hg}\right.$ ), a PIP less than $20 \mathrm{~cm} \mathrm{H}_{2} \mathrm{O}$, and normal or near normal hemodynamic variables.

Crossover studies. To provide for meaningful comparison between CMV and ITPV, we performed crossover studies using three group 2 lambs. Those lambs (with $12.5 \%$ of lungs remaining) had initially been managed with ITPV and had been weaned to room air. We switched quickly from ITPV to CMV at the same PIP and range of RR and monitored over the ensuing minutes changes in gas exchange and hemodynamics. After that, ITPV was resumed in the usual fashion.

Two additional group 2 lambs were initially managed on ITPV until weaned to room air. Those lambs were then switched to CMV at VT and RR sufficient to maintain adequate alveolar ventilation. We closely monitored hemodynamics and gas exchange until death.

Presentation of results. At the time of death, the general appearance of the lung was noted. The lobes were excised and weighed. The weight of the lobes was expressed in grams and in percent of normal. In randomly selected samples, the bloodless lung wet/dry-weight ratio was measured. This ratio was compared with data obtained from healthy lambs used in studies not related to these experiments. Other samples were placed in buffered formaldehyde; sections were taken and stained with hematoxylin and cosin. Where appropriate, data are presented as mean $\pm \mathrm{SD}$.

\section{RISULTS}

The baseline data define a homogeneous population of healthy sheep with a body weight of $10.67 \pm 3.04 \mathrm{~kg}$. With 57,44 , and $19 \%$ remaining lungs managed on conventional $\mathrm{MV}$, all sheep in group 1 were weaned to room air $[\mathrm{PaO})_{2} \geq 6.7 \mathrm{kPa}(50 \mathrm{~mm}$ $\mathrm{Hg}$ ), normal $\mathrm{PaCO}$ ] within $3-46 \mathrm{~h}$ after end of surgery.

All four group 2 sheep with $12.5 \%$ of lungs remaining were weaned to room air on ITPV within $2 \mathrm{~h}$ from the end of surgery. There was no difficulty controlling $\mathrm{PaCO}_{2}, \mathrm{pH}$. or $\left.\mathrm{PaO}\right)_{2}$ with $\mathrm{PIP}$ between 9 and $17 \mathrm{~cm} \mathrm{H}_{2} \mathrm{O}$ ( $2 \mathrm{~h}$ after surgery: $12 \pm 1.6 \mathrm{~cm} \mathrm{H} \mathrm{O}$ ). The mean pulmonary artery pressure immediately after ligation of trachea and respective pulmonary arteries was $40 \pm 5 \mathrm{~mm}$ $\mathrm{Hg}$, with further decrease in pulmonary artery pressure to a mean of $25 \pm 7 \mathrm{~mm} \mathrm{Hg}$ by the end of $6 \mathrm{~h}$ (Fig. 3).

One sheep died with progressive hemodynamic instability $8 \mathrm{~h}$ after surgery (Table 1). At autopsy, the lungs of all sheep except the one sheep referred to (no. 2. Table 1) grossly appeared normal. Histologic sections of the lungs showed normally aerated tissue, with a normal appearance of the terminal bronchioli and alveolar structures. In some areas, the cellularity of the alveolar septa was increased, with some interstitial edema. There was no hemorrhage, atelectasis, overdistension of airway structures, or necrosis of the alveolar septa.

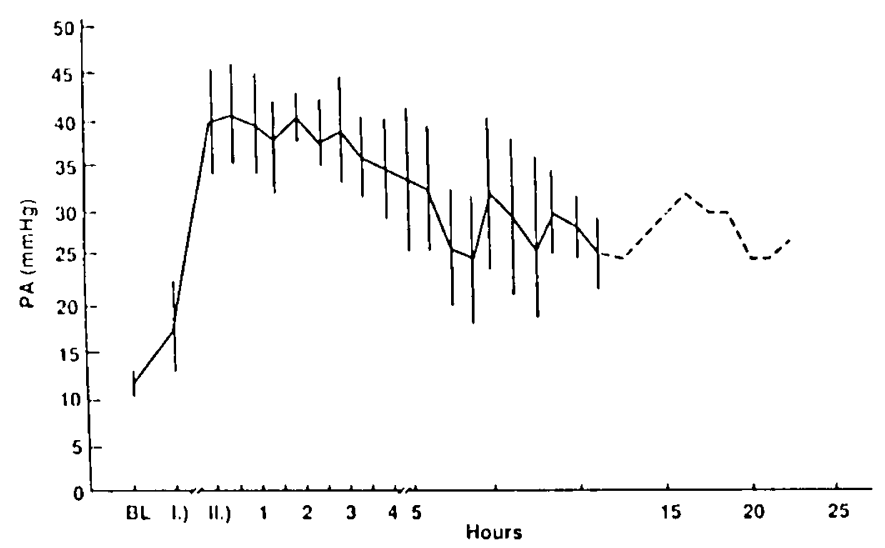

Fig. 3. Mean pulmonary artery pressure (mean $\pm \mathrm{SD}$ ). Group 2 sheep. sheep 1-6. I.). Pulmonary artery ligation to all but the RUL. II.). Pulmonary artery to keft lung ligated, followed by cross clamping the trachea below RUL-bronchus. Bl. Baseline. See text for details.
Crossover studies with RUL. After weaning to room air on ITPV and quickly switching from ITPV to conventional MV. $\mathrm{Pa}\left(\mathrm{O}_{2}\right.$ could no longer be controlled, and the sheep developed severe respiratory acidosis and hemodynamic instability within 40 min of starting conventional MV (sheep no. 1, 3. 4. Table 1). Return to ITPV at the same settings as before was followed by recovery in blood gases within 2-4 min (Fig. 4).

In the second crossover group, arterial blood gases in both lambs remained at $\mathrm{PaO}_{2} / \mathrm{FiO}_{2}$ ratios $>350$ and at normal $\mathrm{Pa}\left(\mathrm{O}_{2}\right.$ values for the first $12 \mathrm{~h}$ (not shown). After that, there was a progressive respiratory acidosis and hypoxia, with death by the end of 18-25 h. At autopsy, the lungs were hemorrhagic and atelectatic, with a liver-like consistency. The histologic sections showed hemorrhage, atelectasis, and massively overdistended peripheral airways and alveolar structures, with necrosis of the alveolar septa, regions of alveoli containing polymorphonuclear leukocytes, and formation of hyaline membranes-all changes indistinguishable from hyaline membrane disease. There was interstitial edema with engorged alveolar septa and hypercellularity of the interstitial tissue, very similar to the observations reported earlier by Carlson at al. (1). The bloodless wet/dry weight ratio was $8.532 \pm 0.277$ (normal: $4.599 \pm 0.259$ ).

\section{DISCUSSION}

This study was designed to explore the minimal fraction of total lung needed to sustain adequate pulmonary ventilation. The group I animal model was a reasonable first approach to address the issue. We surgically removed progressively more lobes of the lungs. By sustaining a VT of 2 times normal, and choosing an appropriately higher RR, we succeded in weaning lambs to room air ventilation with right middle lobe and RUL remaining (19\% lung volume) using conventional MV. We used a VT not over 2 times "normal" times fraction of remaining lung and an RR sufficient to keep PIP within the preselected range. Still, the time for weaning to room air was at times rather prolonged. Animals in both groups 1 and 2 were provided with a tracheostomy, which in itself lowers the dead space. Such reduction is likely to have been beneficial with conventional means of MV but was expected to have no bearing on the efficiency with ITPV.

In group 2 animals, we had removed all but the RUL, or $12.5 \%$ of total lung. The initial mean pulmonary artery pressure was elevated but gradually declined. It was surprising to learn that the RUL vasculature was able to accommodate total cardiac output. without cardiac decompensation. We limited VT to 2.5 $\mathrm{mL} / \mathrm{kg}$, and used RR up to $120 / \mathrm{min}$. the limit set on the Siemens Servo ventilator. An $R R$ in excess of $120 / \mathrm{min}$ would likely have been feasible, since alveolar ventilation improved with rise in $R R$, limited only by the maximal $R R$ of the ventilator. With the RUL alone remaining, adequate ventilation could not be established in group 2 lambs using a conventional mechanical ventilator of the type now often used clinically. The key advantage of ITPV lies in its greatly reduced dead space ventilation, as fresh air/oxygen enters the lungs at the level of the carina. Successful use of the new technique, however, must be predicated on special attention for optimal heating and humidification.

The superiority of ITPV over conventional MV was shown in crossover studies to MV in group 2 sheep previously weaned to room air on ITPV. Gas exchange deteriorated acutely at identical respirator frequency and pressure, only to recover on return to ITPV. When ventilation was limited to conventional MV so as to result in adequate alveolar ventilation, the initial good arterial blood gases declined some hours later and lambs died after $18_{-}$ $25 \mathrm{~h}$ with severe hypercapnia and hypoxia.

Our studies gave us the opportunity to explore how much healthy lung was needed to provide for adequate pulmonary gas exchange. Our studies implicate conventional MV at high PIP in the evolution of acute lung injury and respiratory failure in this animal model. Under identical conditions, we were also able 
Table 1. Tracheal ligation model with RUL (remaining lung $=12.5 \%$ of normal)

\begin{tabular}{|c|c|c|c|c|c|c|c|c|c|c|}
\hline $\begin{array}{c}\text { Sheep } \\
\text { no. }\end{array}$ & $\begin{array}{l}\text { Body weight } \\
\text { (kg) }\end{array}$ & $\begin{array}{l}\text { We } \\
\text { roc } \\
\text { Yes }\end{array}$ & $\begin{array}{l}\text { d to } \\
\text { air } \\
\text { No }\end{array}$ & $\begin{array}{l}\text { Last Pao, } \\
\text { on room } \\
\text { air } \\
\left(\mathrm{mm} \mathrm{Hg}^{*}\right.\end{array}$ & $\begin{array}{l}\text { Time to } \\
\text { death } \\
\text { (h) }\end{array}$ & $\begin{array}{l}\text { Cause of } \\
\text { deatht }\end{array}$ & Weit & $\begin{array}{l}\text { of RUL } \\
\text { normal of } \\
\text { normal }\end{array}$ & $\begin{array}{c}\text { Wet/dry } \\
\text { ratio }\end{array}$ & Gross findings \\
\hline 1 & 14.1 & $x$ & & 79.3 & 5 & 1 & 61.7 & 350 & $6.126: 1$ & $\begin{array}{l}\text { Lung pink, soft, well } \\
\text { acrated, normal ap- } \\
\text { pearance }\end{array}$ \\
\hline 3 & 10.4 & $\times$ & & 100.4 & 22 & 1 & 23.7 & 182 & $4.68: 1$ & $\begin{array}{l}\text { Lung pink. soft, well } \\
\text { aerated, no signs of } \\
\text { barotrauma. normal } \\
\text { appearance }\end{array}$ \\
\hline 4 & 8.9 & $x$ & & 95.9 & 14 & 1 & 26.5 & 238 & 4.8()$: 1$ & $\begin{array}{c}\text { Normal appearance of } \\
\text { the lung. no signs of } \\
\text { barotrauma/injury }\end{array}$ \\
\hline
\end{tabular}

* $1 \mathrm{~mm} \mathrm{Hg}=0.1333 \mathrm{kPa}$.

+ 1. Electively killed: 2. respiratory acidosis/metabolic decompensation: 3. hemodynamic instability.

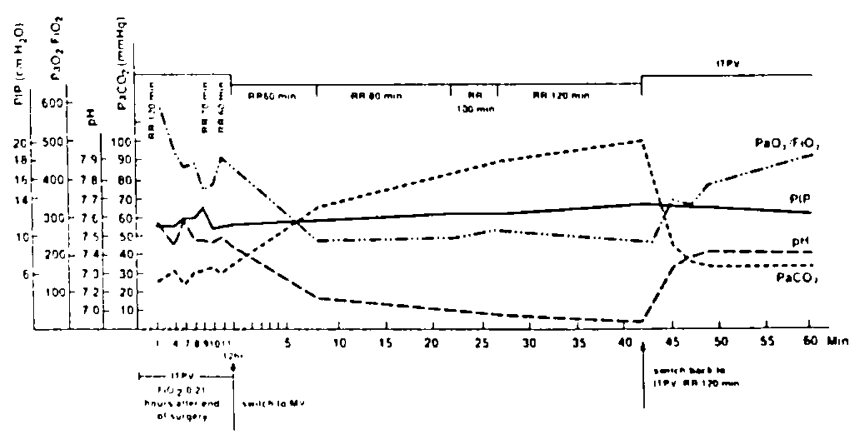

Fig. 4. Crossover studies with the RUL. Changes in $\mathrm{PaO})_{2} / \mathrm{FiO}_{2}, \mathrm{~Pa}$ 'a(O). $\mathrm{pH}$, and PIP after switching from ITPV to MV and back to ITPV, all at the same PIP (VT constant at $2.24 \mathrm{~mL} / \mathrm{kg}=2$ times expected normal for RUL).

to explore the significant benefits of a new mode of ventilation (ITPV) and to assess its safety and efficiency.

In our current studies, all blood flow was directed through the healthy, albeit small, lungs. Such would almost certainly not be the case in the majority of clinical cases when healthy regions of the lungs are interspersed with diseased regions of the lungs. In studies yet to be reported, we have shown that ITPV, at normal PIP, can be successfully applied to the ventilation of lungs with induced diffuse acute disease processes, and even more readily so when only $10 \%$ of lungs are intentionally kept disease free. By keeping the PIP under $20 \mathrm{~cm} \mathrm{H}_{2} \mathrm{O}$, using low PEEP, and avoiding aggressive recruitment at high airway pressures, pulmonary blood flow in a matter of hours is directed to the remaining low resistance, high compliance lung units as reflected in a decrease in venous admixture and dead space ventilation.

These studies may be relevant to the clinical area. It is now widely appreciated that the disease process in acute respiratory failure in newborns, children, and adults is not homogeneous. Areas of consolidation are interspersed with what appears to be normal lung tissue; the amount of normal lung tissue may be reduced to only $10-20 \%(2-14)$. In the clinical setting. the ventilator is attuned to ventilating the lung as a whole. Such an approach is based on practical considerations because it is neither possible nor practical to provide $\mathrm{MV}$ to individual lobes, let alone subunits of the lobes of the lungs. The bulk of MV is directed to the most compliant parts of the lungs, thus also to the healthiest parts. This scenario implies that the truly healthy or healthiest parts of the lungs will be ventilated at nearly the same high pressures used to ventilate the most diseased parts of the lungs, invariably resulting in great distension or overdistension of the previously healthy airway structures and likely in ventilator-induced lung injury. Injury to such lungs can be avoided by optimal ventilation of these remaining healthy parts. Due to the anatomical dead space. conventional MV at low VT (and thus at a low PIP) is often not effective at any RR. With ITPV, normal alveolar ventilation seems possible and practical.

Although quite different in underlying cause, the severely hypoplastic lungs in congenital diaphragmatic hernia present possibilities and limitations (15-25). Compared with conventional MV, ITPV may greatly improve alveolar ventilation, result in lower VT, lower PIP, and lower minute ventilation, and provide the margin where all modes of $\mathrm{MV}$, including neonatal extracorporeal membrane oxygenation, have failed (26).

Our studies show that adequate pulmonary ventilation can be attained in lungs reduced in size to as low as $12.5 \%$ of normal using the newly described method of ITPV. The key advantage of ITPV lies in a greatly reduced anatomical dead space ventilation, permitting the use of an RR of up to $120 / \mathrm{min}$ at normal PIP.

\section{RIIERINCIS}

1. Carlson RF, Charbon BC. Charbon HGiA. Adams WE 1951 The effect of decreasing the amount of lung tissue on the right ventricular pressure in animals. J Thorac Surg 21:621-632

2. Borelli M. Kolobow T. Spatola R. Prato P. Tsuno K 1988 Severe acute respiratory failure managed with continuous positive airway pressure and partial extracorporeal carbon dioxide removal by an artificial membrane lung. $A \mathrm{~m}$ Rev Respir Dis 138:1480-1487

3. Hickling KG 1990) Ventilatory management of ARDS: can it effect the outcome" Intensive Care Med 16:219-226

4. Dreyfuss D. Saumon G 1991 Lung overinflation. Physiologic and anatomic alterations leading to pulmonary edema. In: Zapol WN, lemaire F (eds) Adult Respiratory Distress Syndrome. Mareel Dekher, New York, pp 433 449

5. Taghizadeh A, Reynolds EOR 1976 Pathogenesis of bronchopulmonary dysplasia following hyaline membrane disease. Am J Pathol 82:241-264

6. Bartlett RH, Morris AH, Fairley HB, Hirsch R, O'Connor N, Pontoppidan I 1986 A prospective study of acute hypoxic respiratory failure. Chest 89 : 684-689

7. Artigas A 1988 Adult respiratory distress syndrome: changing concepts of clinical evolution and recovery. In: Vincent JL (ed) Update in Intensive Care and Emergency Medicine 5 . Update 1988. Springer Verlag. Berlin. pp 97114

8. Pesenti A. Kolobow T. Gattinoni L 1988 Extracorporeal respiratory support in the adult. Trans Am Soc Artif Intern Organs 24:1006-1008

9. Kolobow T j9s8 An update on adult extracorporeal membrane oxsgenation: 
extracorporeal $\mathrm{CO}_{2}$ removal. ASAIO Trans 34:1004-1005

10. Kolobow T. Gattinoni L. Solca M. Pesenti A 1989 A new approach to the prevention and the treatment of acute respiratory failure in the adult and the neonate. Appl Cardiopulmonary Pathophysiol 3:135-146

11. Lee PC. Helsmoortel CM, Cohn SM, Fink MP 1990 Are low tidal volumes safe? Chest $97: 430-434$

12. Slutsky AS 1991 Mechanical ventilation. In: Crystal RG, West JB, Barnes PJ, et al (eds) The Lung. Scientific Foundations. Raven Press. New York, pp $2163-2174$

13. Hickling KG, Henderson SJ, Jackson R 1990 Low mortality associated with low volume pressure limited ventilation with permissive hypercapnia in severe adult respiratory distress syndrome. Intensive Care Med 16:372-377

14. Tsuno K. Prato P. Kolobow T 1990 Acute lung injury from mechanical ventilation at moderately high airway pressures. J Appl Physiol 69:956-96!

15. Puri P 1989 Epidemiology of congenital diaphragmatic hernia. In: Puri $P(e d)$ Congenital Diaphragmatic Hernia. Modern Problems in Paediatrics, Vol 24. Basel, Karger, pp 22-27

16. Anderson KB 1986 Congenital diaphragmatic hernia. In: Welch KJ. Randolph JG. Ravitch MM, et al (eds) Pediatric Surgery, 4th Ed. Vol 1. Year Book Medical Publishers, Chicago, pp 589-601

17. Rowe MI, Uribe FL 1971 Diaphragmatic hernia in the newhorn infant: blood gas and pH consideration. Surgery 70:758-761

18. Bloss RS, Aranda JV. Beardmore HE 1981 Congenital diaphragmatic hernia: pathophysiology and pharmacologic support. Surgery 89:518-524
19. Pringle KC 1989 Lung development in congenital diaphragmatic hernia. In: Puri P (ed) Congenital Diaphragmatic Hernia. Nodern Problems in Paediatrics. Vol 24. Karger, Basel, pp $28-53$

20. Cloutier R, Fournier L. Levasseur L 1983 Reversion to fetal circulation in congenital diaphragmatic hernia: a preventable postoperative complication. J Pediatr Surg 18:551-554

21. Srouji MN, Buck B, Downes JJ: Congenital diaphragmatic hernia: deleterious effects of pulmonary interstitial emphysema and tension extrapulmonary air. J Pediatr Surg 16:45-54

22. Wung JT, James S, Kilchersky E, James E 1985 Management of infants with severe respiratory failure and persistence of the fetal circulation, without hyperventilation. Pediatrics $76: 488-494$

23. de Luca U, Cloutier R. Laberge JM, Fournier L. Prendt II, Major D. Edgell D. Roy PE. Roberge S. Guttman FM 1987 Pulmonary barotrauma in congenital diaphragmatic hernia: experimental study in lambs. J Pediatr Surg 22:311-316

24. Gibson C. Fonkalsrud EW 1983 Iatrogenic pneumothorax and mortality in congenital diaphragmatic hernia. J Pediatr Surg 18:555-559

25. Hansen J, James S. Burrington J, Whitfield J 1984 The decreasing incidence of pneumothorax and improving survival of infants with congenital diaphragmatic hernia. J Pediatr Surg 19:385-388

26. Wilson JM. Thompson JR, Schnitzer JJ. Bower LK. Lillehei CW, Perlman ND, Kolobow T 1993 Intratracheal pulmonary ventilation and congenital diaphragmatic hernia: a report of two cases. J Pediatr Surg 28:484-487 